\title{
Aging effect on the low temperature internal friction relaxation peak in a $\mathrm{Ti}_{49} \mathrm{Ni}_{51}$ alloy
}

\author{
H.C. Lin $^{\mathrm{a}, *}$, S.K. Wu ${ }^{\mathrm{b}}$, T.S. Chou ${ }^{\mathrm{c}}$ \\ ${ }^{a}$ Department of Materials Science, Feng Chia University, Taichung 407, Taiwan \\ ${ }^{\mathrm{b}}$ Department of Materials Science and Engineering, National Taiwan University, Taipei 106, Taiwan \\ ${ }^{\mathrm{c}}$ Landsfair Technology Corporation, Kuei Shan, Tao Yuan 333, Taiwan
}

\begin{abstract}
The internal friction relaxation peak appearing around $200 \mathrm{~K}$ in TiNi alloys is associated with the interaction of twin-related dislocations with the pinning agents. The $200 \mathrm{~K}$ relaxation peak in the $400{ }^{\circ} \mathrm{C}$ aged $\mathrm{Ti}_{49} \mathrm{Ni}_{51}$ alloy appears at the R-phase and martensite but not at the B2 phase, since there is no twin-dislocation available in the latter. The sources of the pinning agents are due to the quenched-in vacancies or $\mathrm{Ti}_{11} \mathrm{Ni}_{14}$ precipitate-vacated lattice sites in the matrix. It is found that $400{ }^{\circ} \mathrm{C}$ aging will significantly affect the relaxation characteristic in $\mathrm{Ti}_{49} \mathrm{Ni}_{51}$ alloy. These aging effects on the $200 \mathrm{~K}$ relaxation peak in $\mathrm{Ti}_{49} \mathrm{Ni}_{51}$ alloy will be systematically investigated in this study.
\end{abstract}

(C) 2003 Elsevier Science B.V. All rights reserved.

Keywords: Intermetallics; Dislocations; Strain

\section{Introduction}

The internal friction and shear modulus of TiNi alloys have been investigated by many authors [1-10]. It has been confirmed that the internal friction peaks corresponding to shear modulus minima are associated with the premartensitic and martensitic transformations. In addition to these transformation peaks, a relaxation peak appearing at the temperature around $200 \mathrm{~K}$, and not corresponding to the shear modulus minimum has also been observed [1,3]. Iwasaki and Hasiguti [1] have proposed that the $200 \mathrm{~K}$ peak in TiNi alloys is a thermally activated relaxation peak and is related to dislocations. Zhu et al. [11] reported that the quenched-in vacancies may also be involved in the occurrence of $200 \mathrm{~K}$ peak. However, there has been no systematic investigation of experimental parameters, such as the measuring frequency and strain amplitude of the internal friction test, the thermal-testing history of alloys, etc., on the variation of the $200 \mathrm{~K}$ peak in TiNi alloys. Its characteristics have still not been clarified. In the present

\footnotetext{
*Corresponding author. Tel.: +886-4-2451-7250; fax: +886-4-24510014.

E-mail address: hclin@fcu.edu.tw (H.C. Lin).
}

study, we aim to investigate the aging effect on the $200 \mathrm{~K}$ relaxation peak in $\mathrm{Ti}_{49} \mathrm{Ni}_{51}$ alloy.

\section{Experimental procedure}

The $\mathrm{Ti}_{49} \mathrm{Ni}_{51}$ binary alloys were employed in this study and were prepared by the conventional vacuum arc remelting technique. Titanium (purity, 99.9\%) and nickel (purity, $99.9 \%$ ) for the binary alloys were melted and remelted at least six times in an argon atmosphere. The mass loss during melting was negligibly small. The as-melted buttons were homogenized at $1050{ }^{\circ} \mathrm{C}$ for $72 \mathrm{~h}$ and quenched in water, then hot-rolled to plates with $1 \mathrm{~mm}$ thickness. Specimens with size $110 \times 4 \times 1 \mathrm{~mm}$ for internal friction tests were carefully cut from the plates with a low-speed diamond saw. These specimens were sealed in evacuated quartz tubes, annealed at $800^{\circ} \mathrm{C} \times 2 \mathrm{~h}$ and quenched in water, then aged in the $400{ }^{\circ} \mathrm{C}$ salt-bath for $1-100 \mathrm{~h}$ and quenched in water.

The internal friction measurements were made using an Sinku-Riko $1500-\mathrm{M} / \mathrm{L}$ series inverted torsion pendulum in temperatures ranging from -150 to $100{ }^{\circ} \mathrm{C}$. The measuring frequency was set at about $0.6 \mathrm{~Hz}$ and the changing temperature rate was $2 \mathrm{~K} / \mathrm{min}$. The test strain amplitude 
was $1.66 \times 10^{-3}$ radian $\left(5 \times 10^{-5}\right.$ of maximum true strain). The recording of the data was completely automatic; calculation and plots of internal friction and frequency versus temperature were performed on a digital computer. Thus results with a rather good resolution could be obtained.

\section{Results and discussion}

Fig. 1a,b shows plots of frequency and internal friction versus temperature, respectively, for the as-annealed $\mathrm{Ti}_{49} \mathrm{Ni}_{51}$ specimen. In Fig. 1, peak $\mathrm{P}_{\mathrm{H} 1}$ is at $-92{ }^{\circ} \mathrm{C}$ in heating and peak $\mathrm{P}_{\mathrm{C} 1}$ is at $-95^{\circ} \mathrm{C}$ in cooling. Both peaks correspond to the frequency minima and are associated with the martensitic transformation [5,12]. In addition to $\mathrm{P}_{\mathrm{H} 1}$ and $\mathrm{P}_{\mathrm{C} 1}$ peaks, no other peak can be observed in either heating or cooling.

Fig. 2a,b shows plots of frequency and internal friction versus temperature, respectively, for the $400{ }^{\circ} \mathrm{C} \times 10 \mathrm{~h}$ aged $\mathrm{Ti}_{49} \mathrm{Ni}_{51}$ alloy. In Fig. $2 \mathrm{~b}$, there are three peaks observed in both heating and cooling. Among them, peaks $\mathrm{P}_{\mathrm{H} 1}, \mathrm{P}_{\mathrm{H} 2}$, $\mathrm{P}_{\mathrm{HR}}$ appear in heating at 12,38 and $-61{ }^{\circ} \mathrm{C}$, respectively, and peaks $\mathrm{P}_{\mathrm{C} 1}, \mathrm{P}_{\mathrm{C} 2}, \mathrm{P}_{\mathrm{CR}}$ appear in cooling at $-90,36$ and $-52{ }^{\circ} \mathrm{C}$, respectively. Peaks $\mathrm{P}_{\mathrm{H} 1}, \mathrm{P}_{\mathrm{H} 2}, \mathrm{P}_{\mathrm{C} 1}$ and $\mathrm{P}_{\mathrm{C} 2}$ all correspond to the minima of frequency $f$ in Fig. $2 \mathrm{a}$ and are identified as the transformation peaks. Peaks $\mathrm{P}_{\mathrm{H} 1}$ and $\mathrm{P}_{\mathrm{C} 1}$ are associated with the martensitic transformation and peaks $\mathrm{P}_{\mathrm{H} 2}$ and $\mathrm{P}_{\mathrm{C} 2}$ are associated with the premartensitic $\mathrm{R}$-phase transformation [5,12]. However, peaks $\mathrm{P}_{\mathrm{HR}}$ and $\mathrm{P}_{\mathrm{CR}}$ do not correspond to the frequency minima, and are considered to be the relaxation-type internal friction peaks. Carefully examining Fig. 2b, we find that peak $\mathrm{P}_{\mathrm{CR}}$ appears in the premartensite $\mathrm{R}$ phase and peak $\mathrm{P}_{\mathrm{HR}}$ in the martensite phase. Therefore, the relaxation peak can appear in the $\mathrm{R}$ phase or in the martensite phase. Moreover, by plotting the Arrhenius graph relating the reciprocals of peak temperatures to the logarithms of vibration frequencies, the activation energy $Q$ and frequency factor $f_{0}$ for the relaxation peak are calculated to be $Q=0.39 \mathrm{eV}$ and $f_{0}=6.2 \times 10^{9} \mathrm{~s}^{-1}$ (H.C. Lin, S.K. Wu, T.S. Chou, unpublished research, 2002). These features indicate that the $200 \mathrm{~K}$ relaxation peak is related to the thermally activated process.

Fig. 3a,b shows the same plots as Fig. 2a,b, but now for the $400{ }^{\circ} \mathrm{C} \times 100 \mathrm{~h}$ aged $\mathrm{Ti}_{49} \mathrm{Ni}_{51}$ alloy. In Fig. 3, peaks $\mathrm{P}_{\mathrm{H} 1}, \mathrm{P}_{\mathrm{H} 2}, \mathrm{P}_{\mathrm{HR}}, \mathrm{P}_{\mathrm{C} 1}, \mathrm{P}_{\mathrm{C} 2}$, and $\mathrm{P}_{\mathrm{CR}}$ are located at 24, 46, - 64, $-32,42$ and $-64{ }^{\circ} \mathrm{C}$, respectively. Both peaks $\mathrm{P}_{\mathrm{HR}}$ and $\mathrm{P}_{\mathrm{CR}}$ appear in the martensite phase. The experimental results of $400{ }^{\circ} \mathrm{C} \times 5 \mathrm{~h}$ and $400{ }^{\circ} \mathrm{C} \times 20 \mathrm{~h}$ aged $\mathrm{Ti}_{49} \mathrm{Ni}_{51}$ alloys are very similar to those of specimens aged $10 \mathrm{~h}$ and $100 \mathrm{~h}$ with the exception of small shifts in peak temperatures and peak heights $Q_{\max }^{-1}$.

Fig. 4 shows the effect of aging time on the relaxation peak height $Q_{\max }^{-1}$ in the $400{ }^{\circ} \mathrm{C}$ aged $\mathrm{Ti}_{49} \mathrm{Ni}_{51}$ alloy. Fig. 4 a is the plot of internal friction $Q^{-1}$ versus temperature under various aging times, and Fig. $4 \mathrm{~b}$ is the plot of $\mathrm{P}_{\mathrm{HR}}$ peak height $Q_{\max }^{-1}$ versus aging time. From Fig. 4, we find that the $Q_{\max }^{-1}$ of the peak $\mathrm{P}_{\mathrm{HR}}$ increases sharply in the beginning $10 \mathrm{~h}$ of aging and then approaches the steady value for further aging.

It is well known that the martensite phase [13-17] and the premartensite R-phase [18] in TiNi alloys consist of twin-related plates in which self-accommodating groups are formed. These twin-related plates are themselves further subdivided into smaller units which are again twin-related along the same planes. Based on the previous investigations $[1,3,11]$, it is reasonable to suggest that a high density of twin-dislocations exists in the martensite and premartensite phases. As shown in Fig. 1, there is no relaxation peak being observed in either heating or cooling for the as-quenched $\mathrm{Ti}_{49} \mathrm{Ni}_{51}$ specimen. This may come from the fact that the appearing temperature of relaxation peak $\mathrm{P}_{\mathrm{R}}$, about $200 \mathrm{~K}$, is now located in the parent $\mathrm{B} 2$ phase, but not in the martensite or premartensite phase (in Fig. $1, \mathrm{P}_{\mathrm{H} 1}$ is at $-92{ }^{\circ} \mathrm{C}$ and $\mathrm{P}_{\mathrm{C} 1}$ is at $\left.-95^{\circ} \mathrm{C}\right)$. In the $\mathrm{B} 2$ phase, there are no twin-related plates, i.e. no twin-related dislocation exists, therefore, the dislocation involved relaxation peak cannot appear. From the viewpoint of twindislocations, the relaxation peak $\mathrm{P}_{\mathrm{R}}$ of the TiNi alloys can appear only in the martensite or premartensite phase, but not in the B2 phase. The results shown in Figs. 2 and 3 also support this suggestion.

The model proposed by Kochler [19] and developed by Granato and Lücke [20] has been made to explain the relaxation of dislocations with point defects. In which, the damping capacity $Q^{-1}$ of the metals can be divided into two components, $Q_{i}^{-1}$ and $Q_{h}^{-1}$, with the former being independent of amplitude, and the latter being dependent on amplitude. The model has the form shown in Eq. (1):

$$
\begin{aligned}
Q^{-1} & =Q_{i}^{-1}+Q_{h}^{-1} \\
& =A_{1} \rho \ell^{4}+\left(A_{2} \rho L^{3} / \varepsilon \ell^{2}\right) \exp \left(-A_{3} / \varepsilon \ell\right)
\end{aligned}
$$

where

$\rho$ : dislocation density

$L$ : the length of the unmovable dislocation segment

$\ell:$ the average loop length

$\varepsilon$ : amplitude

$A_{1}, A_{2}$ and $A_{3}$ are factors depending on materials and pinning points.

The relationship between the relaxation peak height and the physical parameters seems very complicated at the first glance. It is reported that the $200 \mathrm{~K}$ peak in TiNi alloys is an amplitude-independent relaxation [11]. This argument is also confirmed in our unpublished research. Therefore, Eq. (1) can be simplified into the form as:

$Q^{-1}=A \rho \ell^{4}$

The peak height is thus highly dependent on the disloca- 

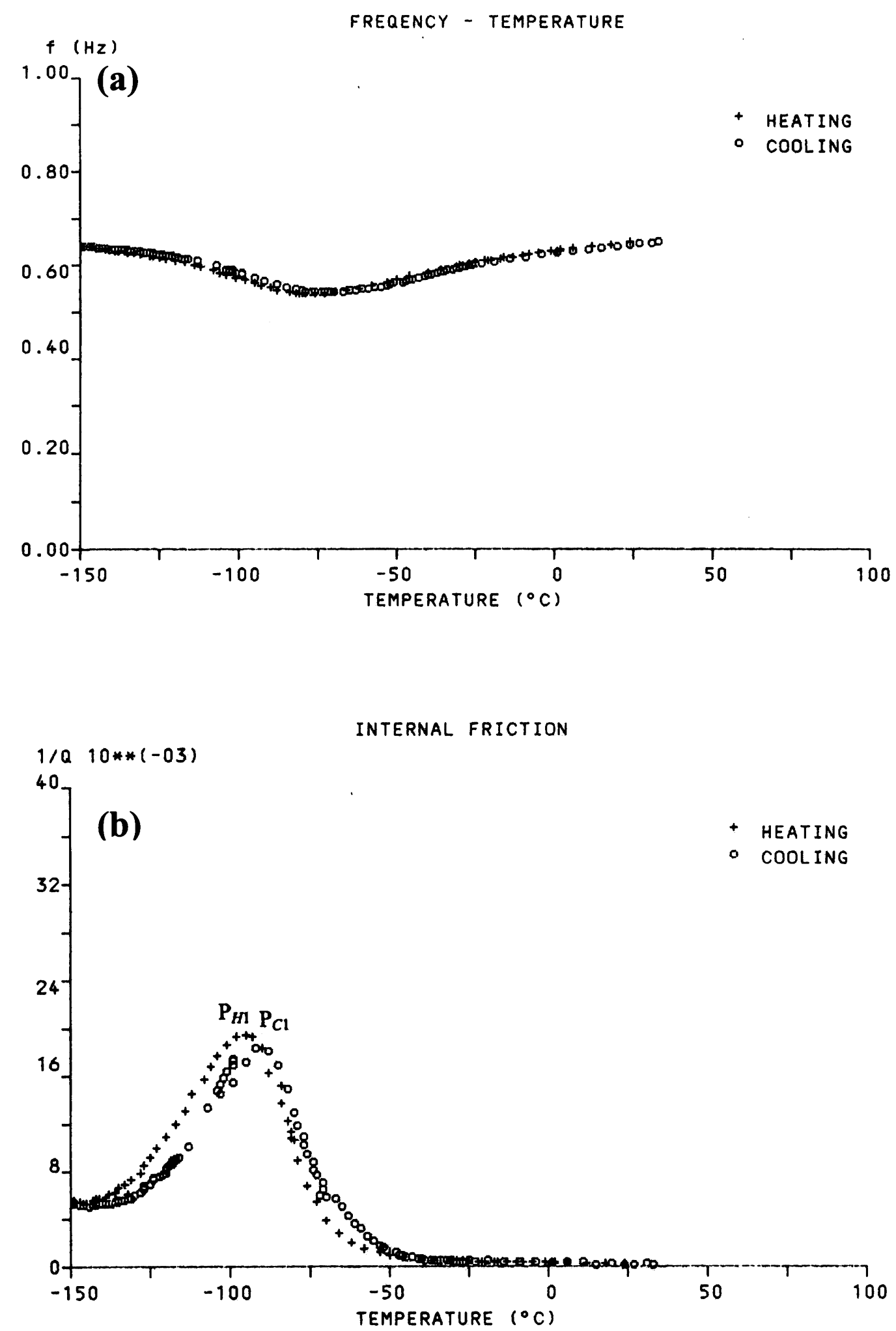

Fig. 1. (a) Frequency, (b) internal friction versus temperature curves for the solution treated $\mathrm{Ti}_{49} \mathrm{Ni}_{51}$ specimen.

tion density and the loop length for ongoing of pinningunpinning mechanism during the cyclic vibration of internal friction test. In Fig. 5, a single unmovable dislocation segment initially is pinned along its length by a number of point defects. Under an increasing shear stress, the dislocation segment bows out from the pinning points, as shown in Fig. 5a. At a critical value of stress $(c \rightarrow d)$, the whole segment is catastrophically torn away from the row of 


\section{$f(\mathrm{~Hz})$}
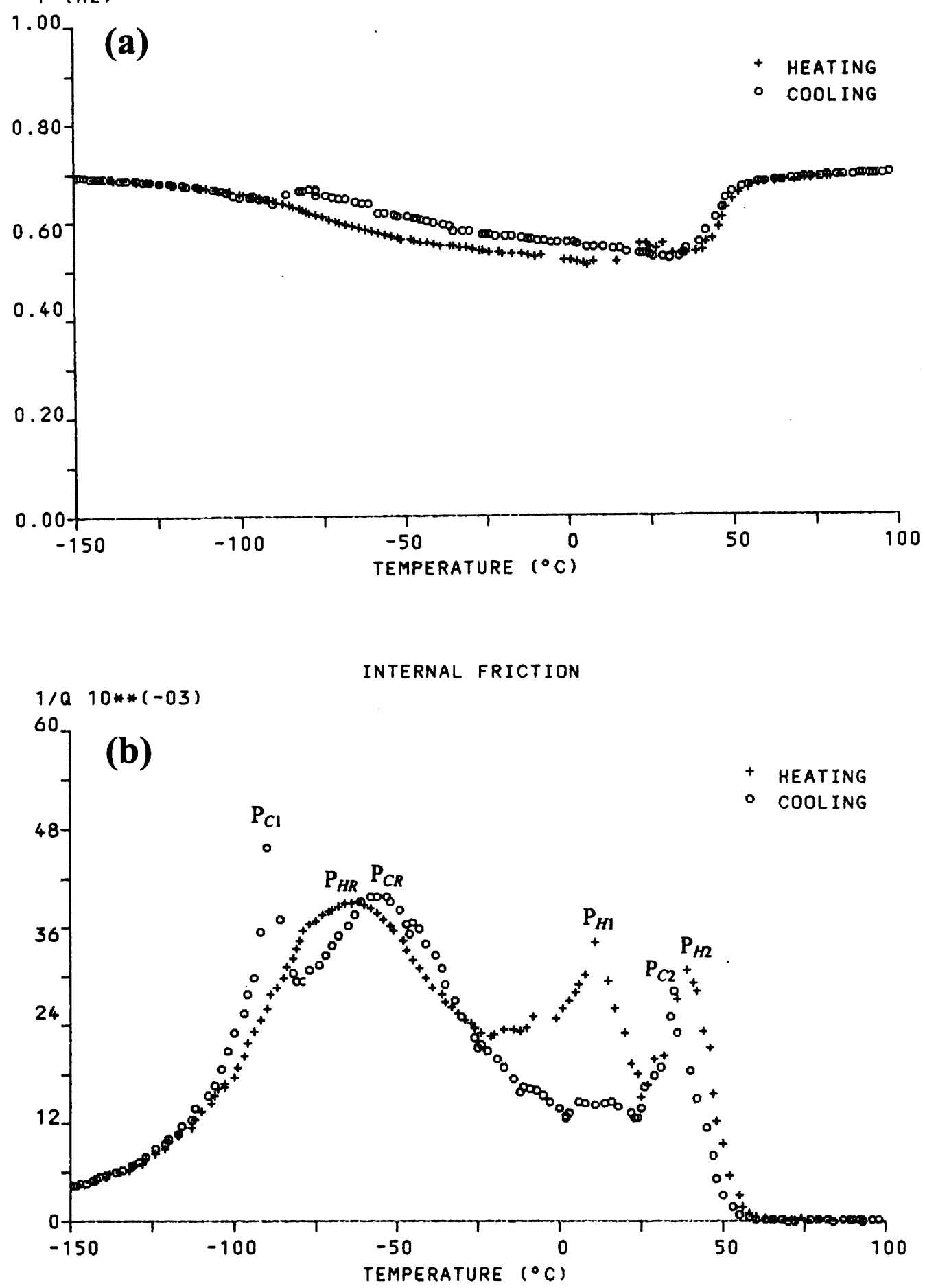

Fig. 2. (a) Frequency, (b) internal friction versus temperature curves for the $400{ }^{\circ} \mathrm{C} \times 10 \mathrm{~h}$ aged $\mathrm{Ti}_{49} \mathrm{Ni}_{51}$ alloy.

pinning points. During unloading, the material consequently responds down to zero stress with a lower effective modulus $(\mathrm{d} \rightarrow \mathrm{e} \rightarrow \mathrm{f})$. The energy dissipated per unit volume in one complete cycle is given by twice the shaded area, $\Delta E_{1}$ in Fig. $5 b$.

According to Eq. (2), the $Q_{\max }^{-1}$ value should increase with increasing dislocation density and dislocation loop length. However, there is a critical range of the loop length $\ell$ for the generation of the relaxation peak, which should not be ignored. When $\ell$ is very large, i.e. the amount of pinning points is small, the number of dislocation loops pinned by point defects which are responsible for the 

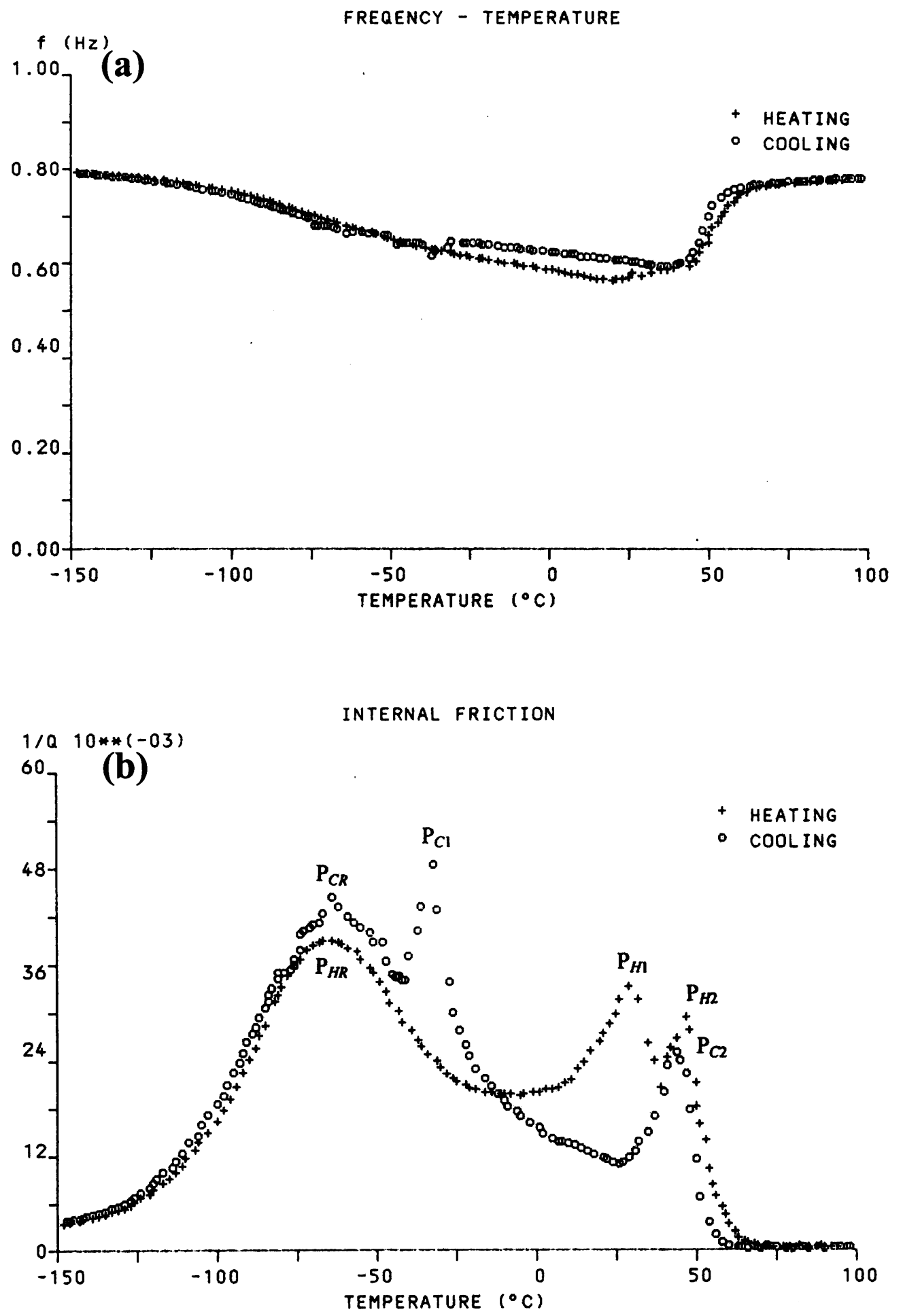

Fig. 3. (a) Frequency, (b) internal friction versus temperature curves for the $400{ }^{\circ} \mathrm{C} \times 100 \mathrm{~h}$ aged $\mathrm{Ti}_{49} \mathrm{Ni}_{51}$ alloy.

relaxation peak is too small to give rise to an experimentally detectable peak. On the other hand, when $\ell$ is very small, dislocations with very high amounts of point defects are pinned so densely that they cannot be unpinned with the help of measured stress. Thus the peak cannot be observed in this case. It should be expected therefore that there exists an optimum range of point defects for the appearance of the peak.

As mentioned above, the $200 \mathrm{~K}$ relaxation peak is generated after the aging treatment on $\mathrm{Ti}_{49} \mathrm{Ni}_{51}$ alloy, implying that the pinning force should be too weak to cause effective pinning before aging. In fact, there is 


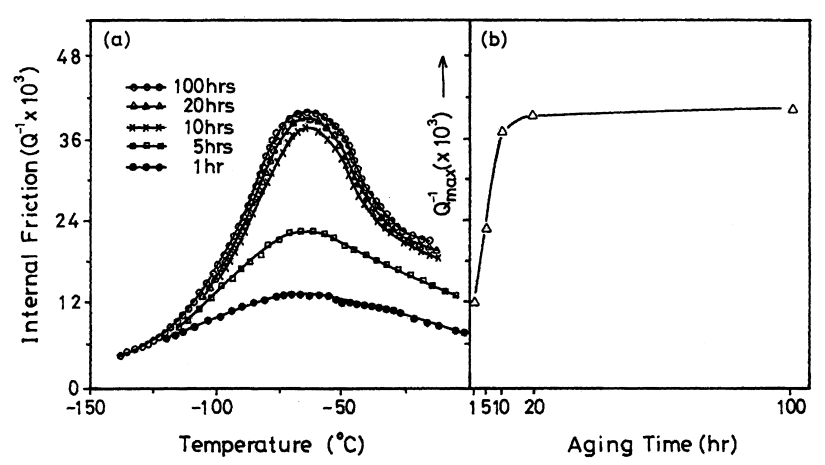

Fig. 4. (a) The relaxation peak versus temperature curves for $\mathrm{Ti}_{49} \mathrm{Ni}_{51}$ specimens which have subjected to various aged time at $400{ }^{\circ} \mathrm{C}$, (b) The variation of the relaxation peak height $Q_{\max }^{-1}$, with the aging time for the $400{ }^{\circ} \mathrm{C}$ aged $\mathrm{Ti}_{49} \mathrm{Ni}_{51}$ specimen.

neither twin-dislocations nor pinning agents for the generation of $200 \mathrm{~K}$ peak before aging treatment. After aging treatment, there are a considerable number of vacancies in the matrix induced by the coarsening of the $\mathrm{Ti}_{11} \mathrm{Ni}_{14}$ precipitates, which would be able to pin up the transformation induced twin-dislocations to cause relaxation damping. After a prolonged aging, say $20 \mathrm{~h}$ in this study, the growth of precipitates slows down [21] and the vacancy concentration tends to approach a constant. As a consequence, the peak height of $P_{R}$ approaches a steady value, as shown in Fig. 4 b.

It may seem confusing that prolonged aging of the

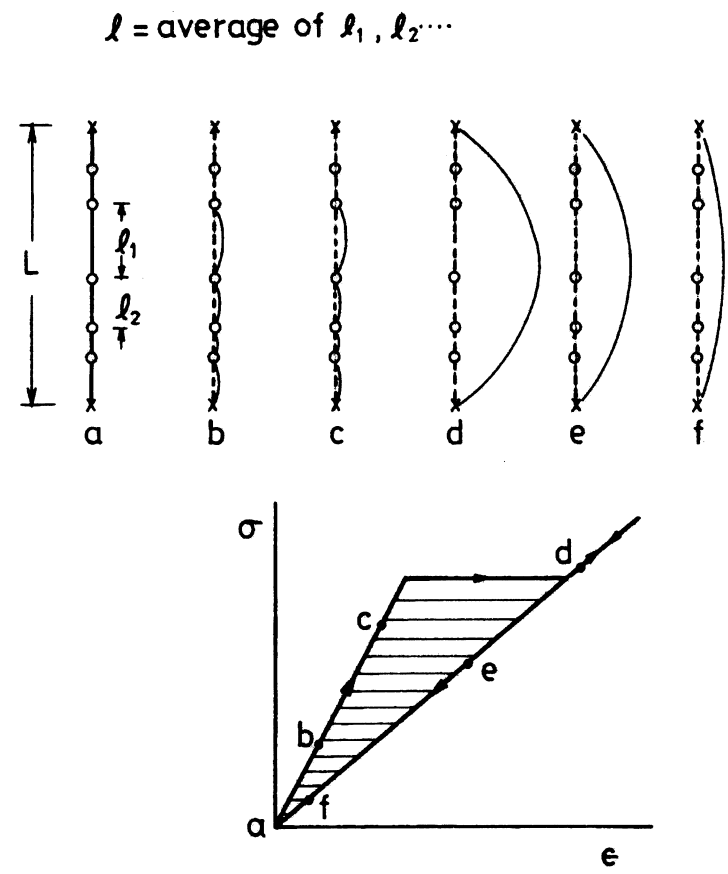

(a)

(b)

Fig. 5. (a) Unpinning sequence of a Granato-Lücke type pinned dislocation segment during a loading cycle. (b) The corresponding stress-strain curve and hysteresis loop. The lettered points match the sequence $\mathrm{a}-\mathrm{f}$ in (a). (After Granato and Lücke, for more explanation please refer to Ref. [17]).
$\mathrm{Ti}_{49} \mathrm{Ni}_{51}$ alloy would increase the vacancy concentration which will shorten the loop length $\ell$ and thus decrease the relaxation peak height. However, it is possible that the loop length $\ell$ in the aged $\mathrm{Ti}_{49} \mathrm{Ni}_{51}$ alloy may not be short enough to fix the dislocation segments. In addition, the coarsened $\mathrm{Ti}_{11} \mathrm{Ni}_{14}$ precipitates could provide a much wider slip area for the bow-out of dislocation segments to carry out the completed pinning-unpinning reaction, and therefore could result in a larger energy loss. In contrast, the shortly aged $\mathrm{Ti}_{49} \mathrm{Ni}_{51}$ sample with the finely and condensely dispersed precipitates would be detrimental to the complete unpinning of the dislocation loop from the original pinning agents, thus creating a lower peak height.

Fig. 6 illustrates the proposed effect of precipitated morphology on the unpinning mechanism. In the case of fine precipitation with short aging time, the complete bow-out of pinned dislocation is retarded by the $\mathrm{Ti}_{11} \mathrm{Ni}_{14}$ particles. On the other hand, prolonged aging leading to a coarse $\mathrm{Ti}_{11} \mathrm{Ni}_{14}$ distributed morphology would provide a wider slip area for the unpinning reaction. Obviously, the use of a modified K-G-L model can roughly interpret the change of $200 \mathrm{~K}$ peak height. However, the details of the microstructure could affect the unpinning mechanism, and thus cause a deviation from the K-G-L relation. Care must also be taken to relate the dislocation density as part of the pinnable-unpinnable dislocations rather than the entire dislocation density being effective in the matrix.

(a)

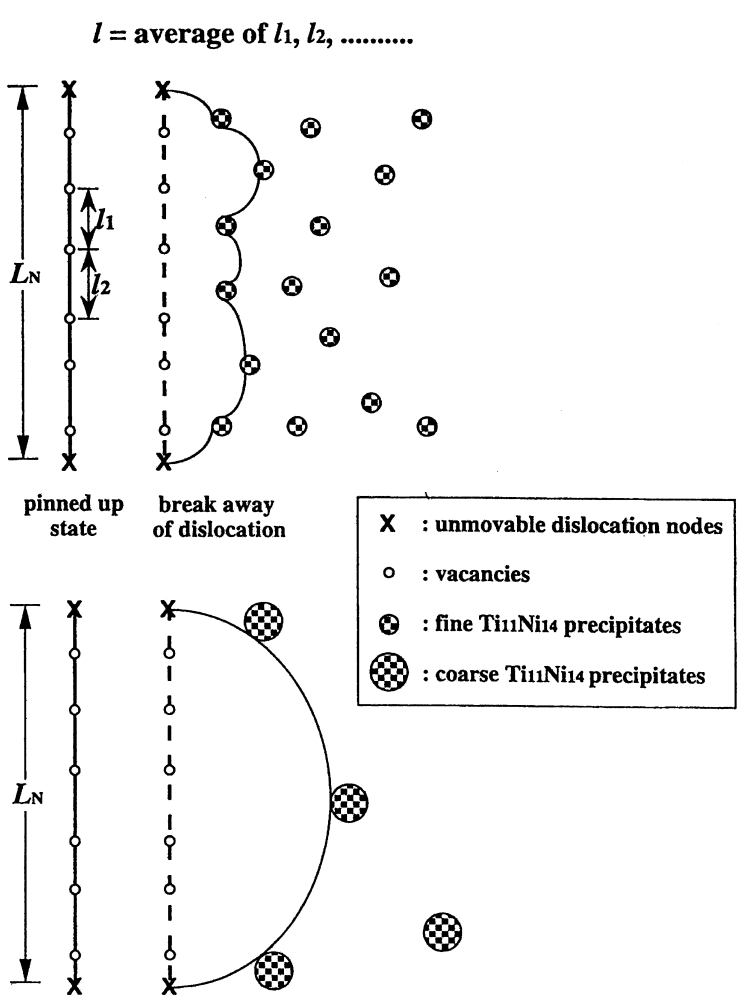

Fig. 6. The proposed effect of precipitation morphology on the bow out of pinned-up dislocations by vacancies for (a) fine $\mathrm{Ti}_{11} \mathrm{Ni}_{14}$ precipitated condition, (b) coarse $\mathrm{Ti}_{11} \mathrm{Ni}_{14}$ precipitated condition. 


\section{Conclusion}

The $200 \mathrm{~K}$ relaxation peak in $\mathrm{Ti}_{49} \mathrm{Ni}_{51}$ alloy is associated with the interaction of twin-related dislocations with the pinning agents by quenched-in vacancies or $\mathrm{Ti}_{11} \mathrm{Ni}_{14}$ precipitate-vacated lattice sites. The $200 \mathrm{~K}$ relaxation peak can be located at the R-phase or martensite phase but not at the B2 phase, since there is no twin-dislocations available in the latter. The sources of the vacancies are due to quenched-in vacancies or $\mathrm{Ti}_{11} \mathrm{Ni}_{14}$ precipitate-vacated lattice sites in the matrix. It is found that aging will affect relaxation characteristic in $\mathrm{Ti}_{49} \mathrm{Ni}_{51}$ alloy. The longer the $400{ }^{\circ} \mathrm{C}$ aging, the higher its relaxation peak will be. The fine $\mathrm{Ti}_{11} \mathrm{Ni}_{14}$ precipitates in the aged $\mathrm{Ti}_{49} \mathrm{Ni}_{51}$ alloy, although not directly present in the dislocation motion at the early stage, form obstacles which retard the unpinning of the dislocation, thereby causing a decrease in peak height.

\section{Acknowledgements}

The authors sincerely acknowledge the financial support of this study by the National Science Council (NSC), Republic of China, under Grant NSC 85-2216-E002-023.

\section{References}

[1] K. Iwasaki, R. Hasiguti, Trans. JIM 28 (1987) 363.

[2] O. Mercier, K.N. Melton, Y. De Preville, Acta Met. 27 (1979) 1467.

[3] Y.T. Huang, G.P. Yang, P. He, Scripta Met. 19 (1985) 1033; Y.T. Huang, G.P. Yang, P. He, Scripta Met. 19 (1985) 1039.

[4] N.Y. Chui, Y.T. Huang, Scripta Met. 21 (1987) 447.

[5] S.K. Wu, H.C. Lin, T.S. Chou, Acta Metall. 38 (1990) 95.

[6] H.C. Lin, S.K. Wu, T.S. Chou, Acta Metall. 39 (1991) 2069.

[7] V. Pelosin, A. Riviere, Met. Mater. Trans. A 29A (1998) 1175.

[8] B. Coluzzi, A. Biscarini, R. Campanella, L. Trotta, G. Mazzolai, A. Tuissi, F.M. Mazzolai, Acta Mater. 47 (1999) 1965.

[9] I. Yoshida, T. One, M. Asai, J. Alloys Comp. 310 (2000) 339.

[10] B. Coluzzi, A. Biscarini, R. Campanella, G. Mazzolai, L. Trotta, F.M. Mazzolai, J. Alloys Comp. 310 (2000) 300.

[11] J.S. Zhu, R. Schaller, W. Benoit, Phys. Lett. A 141 (1989) 177.

[12] S.K. Wu, H.C. Lin, T.S. Chou, Scripta Met. 23 (1989) 2042.

[13] C.M. Jackson, H.J. Wanger, R.J. Wasilewski, NASA-SP (1972) 5110.

[14] G.D. Sandrock, A.J. Perkins, R.G. Hehemanm, Met. Trans. 2 (1971) 2769.

[15] J. Perkins, Met. Trans. 4 (1973) 2709.

[16] H.A. Mohamed, J. Washburn, J. Mater. Sci. 12 (1977) 469.

[17] T. Saburi, S. Nenno, in: Proc. of Int. Conf. on Solid to Solid Phase Trans., ASM, 1982, p. 1455.

[18] S. Miyazaki, C.M. Wayman, Acta Metall. 36 (1988) 181.

[19] J.S. Kochler, in: Imperfections in Nearly Perfect Crystals, Wiley, New York, 1952, Chapter 7.

[20] A.V. Granato, K. Lücke, J. Appl. Phys. 27 (1956) 583; A.V. Granato, K. Lücke, J. Appl. Phys. 27 (1956) 789.

[21] W.C. Leslie, Acta Metall. 9 (1961) 1004. 